Reservas políticas e efeitos de spillover: Exposição cruzada reduz viés eleitoral contra mulheres?

Yuri Chagas Lopes

Brasília, 2015. 


\section{Reservas políticas e efeitos de spillover: Exposição cruzada reduz viés eleitoral contra mulheres?}

Dissertação apresentada como requisito para obtenção do título de Mestre em Economia pelo Programa de Pós-Graduação em Economia da Universidade de Brasília.

Yuri Chagas Lopes

Orientador: Professor Doutor Michael

Christian Lehmann 


\section{Introdução}

Diversos países em desenvolvimento são afetados por um duradouro e significante viés contrário a lideranças femininas. Tentativas de reduzir ou mesmo eliminar este viés são importantes, não apenas de um ponto de vista ético, mas também por razões tradicionalmente econômicas: exclusão social pode afetar o bem-estar de uma economia e interferir em sua estabilidade social (KROOK, 2009).

Palco de uma abrangente descentralização política na década de 1990, a experiência indiana é de especial relevância. Sua legislação eleitoral obriga uma parcela das posições de liderança local a serem reservadas para mulheres e outros grupos considerados em desvantagem. Todo este processo de reservas é executado de modo aleatório, abrindo espaço para interpretações de causalidade entre localidades reservadas (tratamento) e não reservadas (controle).

A literatura sobre as cotas eleitorais indianas engloba contribuições a respeito de seu impacto sobre a oferta de bens públicos (CHATTOPADHYAY e DUFLO, 2004), alterações de comportamento político em relação a lideranças femininas (BEAMAN et al., 2009), qualidade dos candidatos (BAN e RAO, 2008), direcionamento de gastos e transferências sociais (PANDE, 2003) e sua capacidade de perpetuação (BHAVNANI, 2009).

Pouca atenção é dada, no entanto, aos efeitos de spillover das cotas de gênero: a proximidade geográfica entre vilarejos tratados e não tratados, assim como a possibilidade de mudança de estado de tratamento com a sucessão de eleições ao longo do tempo, cria cenário para potencial efeitos de spillover. Especialmente relevantes são os possíveis efeitos de spillover sobre a forma como os habitantes dos vilarejos percebem e avaliam a efetividade das lideranças femininas, haja vista o papel central dos vieses para a sub-representatividade política do gênero.

Utilizando a base de dados disponibilizada por Beaman et al. (2009), a qual conta com resultados eleitorais e informações sobre reservas políticas para todos os 165 GPs do distrito de Birbhum, no estado de Bengala Ocidental, ampliam-se as principais regressões originais dos autores por meio da metodologia apresentada em Miguel e Kremer (2004). Utilizando variáveis de densidade total de tratados para verificar possíveis efeitos de spillover decorrentes da proximidade geográfica dos vilarejos reservados e não reservados, analisam-se os impactos indiretos da política de reservas 
para mulheres sobre a capacidade de participação política feminina, assim como sobre a percepção de sua efetividade.

Os resultados encontrados não indicam efeitos de spillover das reservas sobre o número de mulheres que se candidatam ou vencem eleições para conselhos em GPs que não estão reservados durante as eleições de 2008. No entanto, são encontrados efeitos significativos e significantes de spillovers sobre a percepção dos habitantes masculinos a respeito da capacidade de mulheres enquanto líderes políticos. O viés inicial contrário à lideranças femininas verificado em Beaman et al. (2009) pode ser reduzido em cerca de $12 \%$ em GPs que nunca foram reservados, simplesmente por estar próximo de outros GPs que receberam reservas em ao menos uma das eleições anteriores.

Além disso, percebe-se que a inclusão de variáveis que tentam captar efeitos de spillover apresentam potencial melhora na especificação dos modelos de avaliação dos efeitos da política pública em questão. Os níveis de significância e as magnitudes dos estimadores dos efeitos diretos das reservas políticas para mulheres sobre a redução de viés eleitoral são potencialmente melhorados.

Na seção seguinte, realiza-se uma breve revisão geral a respeito da política de cotas de gênero, suas motivações, justificativas e impactos. A terceira seção, por sua vez, aprofunda a análise do Panchayat e discute a razoabilidade das cotas de gênero neste contexto. Na quarta seção, introduz-se a literatura sobre efeitos de spillover em políticas públicas, discutindo-se ainda o potencial de spillovers apresentado pela política de reservas para mulheres na Índia. A quinta seção apresenta a metodologia empregada neste trabalho, passando pela base de dados e especificações de regressões, assim como os principais resultados encontrados. A sexta seção conclui o trabalho, reforçando a importância da consideração de efeitos de spillover e a possibilidade de futuros estudos sobre a política de cotas de gênero indiana.

\section{Cotas eleitorais de gênero e lideranças femininas}

A existência de distinções marcantes entre os gêneros, as quais estão comumente enraizadas em questões socioculturais e tendem a persistir ao longo do tempo, levou mais de 100 países a adotarem políticas que garantissem uma certa parcela de posições políticas para mulheres (KROOK, 2009). 
As preferências médias femininas podem diferir de forma bem marcada daquelas comumente percebidas entre homens, diferenças estas com potenciais efeitos sobre as decisões tomadas internamente pelas famílias, assim como sobre resultados políticos em processos democráticos (EDLUND e PANDE, 2002).

Muito embora os modelos tradicionais de economia política que supõem comprometimento pré-eleitoral com determinadas campanhas políticas, como o do eleitor mediano desenvolvido em Downs (1957), levem a conclusões de que características dos políticos (gênero incluso) não afetem as políticas resultantes; a evidência empírica disponível não tende a corroborar esta conclusão (LEVITT, 1996; PANDE, 2003). Modelos do tipo "candidato-cidadão" formalizam a ideia de que a identidade dos políticos pode sim ser importante para a determinação das políticas resultantes (OSBORNE e SLIVINSKI, 1996; BESLEY e COATE, 1997).

Diversas sociedades são caracterizadas por sub-representação de mulheres em instituições responsáveis pelo processo de elaboração de políticas públicas, tanto em nível nacional quanto local. Quando a identidade do político importa e a falta de representatividade feminina é ocasionada por barreiras institucionais, normas culturais ou mera discriminação política (vieses contrários a lideranças femininas); ações afirmativas com objetivo de elevar a parcela de participação feminina são capazes de afetar a natureza do equilíbrio político e, consequentemente, produzir resultados de longo prazo (KROOK, 2009).

Nas palavras de Beaman et al. (2009, p 1497),

"[a] crença de que o gênero do político possa ter importantes consequências para decisões de políticas públicas, e a possibilidade de que tais vieses, caso existentes, possam ser maleáveis; tem levado formuladores de políticas públicas a enfatizar a importância de apoiar grupos femininos iniciais de políticos. A suposição é que, uma vez que os eleitores aprendam que mulheres são capazes de liderar efetivamente, vieses de gênero na política diminuirão." ${ }^{1}$

Mundo afora, estudos sugerem que a elevação da participação feminina nos processos legislativos contribuiu para a redução (ou mesmo supressão) do viés de gênero no que tange ao acesso a serviços específicos. Além disso, constata-se uma

\footnotetext{
${ }^{1}$ Tradução livre do autor.
} 
tendência exibida por legisladoras femininas em alocar mais recursos públicos para causas consideradas importantes por mulheres (SAINT-GERMAN, 1989; REINGOLD, 1992; CHATTOPADHYAY e DUFLO, 2004).

Há ainda evidências de que maiores níveis de representação feminina nos poderes legislativo e executivo estão associados a menores níveis de corrupção, assim como mais gastos por aluno matriculado no sistema público de ensino, maiores parcelas de professoras e melhores taxas de matrícula de garotas no ensino médio (DOLLAR et al, 2001; BROLLO e TROIANO, 2013).

Lott e Kenny (1999) sugerem que a própria ampliação do direito ao voto para mulheres nos Estados Unidos levou ao aumento do gasto público e padrões de votação mais liberais, fenômeno este que persistiu ao longo do tempo à medida que as mulheres gradualmente iam percebendo e se apropriando dos benefícios conferidos pelo direito ao voto. Resultado similar é obtido em Miller (2008), o qual nota que, ao longo da história norte americana, a promulgação de leis estendendo o direito ao voto para mulheres foi comumente seguida por mudanças no comportamento do legislativo e grandes aumentos dos gastos locais com saúde pública.

\subsection{O sistema indiano de cotas: reservas políticas no Panchayat}

O sistema de Panchayat é um modelo de governança descentralizado, baseado em conselhos organizados a nível de vilarejos (Gram Panchayats, doravante GPs), "quarteirões" (Panchayat Samiti) e distritos (Zilla Parishad). Os membros destes conselhos, eleitos por voto popular, são responsáveis pela administração dos bens públicos locais. Cada GP engloba entre 1.000 e 10.000 habitantes, distribuídos dentre 1 a 15 vilarejos. Os GPs não tem jurisdição sobre áreas urbanas, as quais são administradas separadamente por municipalidades.

Eleitores elegem um conselho e, seja direta ou indiretamente, um Pradhan (representante de cargo hierárquico mais elevado em um GP) e um Upa-Pradhan (segundo cargo hierárquico mais alto). Os candidatos são geralmente nomeados pelos partidos locais, mas devem respeitar a condição de serem residentes dos vilarejos que representam.

O conselho toma decisões por meio de voto majoritário, sendo que o Pradhan não possui qualquer poder de veto. O Pradhan, no entanto, é o único membro cuja duração do cargo equivale ao termo de gestão do conselho (cinco anos). Compete aos GPs administrarem os bens públicos em sua área de atuação (edifícios públicos, estradas 
e água), monitorar os funcionários públicos e identificar os potenciais beneficiários dos diversos programas de transferência vigentes na Índia.

A principal fonte de recursos dos GPs fica por cargo de transferências recebidas dos estados, as quais são alocadas em quatro grandes programas: o Jawhar Rozgar Yojana, para infraestrutura geral; um pequeno programa complementar para água potável; fundos para programas de assistência social; e recursos para o funcionamento interno dos GPs. Em princípio, cada GP tem total flexibilidade na alocação destes recursos.

O Panchayat é obrigado a realizar duas reuniões por ano entre habitantes e chefes de vilarejos, as Gram Samsad, nas quais todos os eleitores podem participar. Durante estas reuniões, o conselho de cada GP relata suas atividades durante os seis meses anteriores e apresenta o orçamento proposto para os seis meses seguintes. $\mathrm{O}$ Pradhan também é responsável por estabelecer horários de atendimento aos habitantes dos vilarejos.

Apesar de o Panchayat existir desde a instauração da atual Constituição da Índia em 1949, foi em 1992, com o advento da 73ª Emenda à Constituição da Índia, que se instaurou a obrigatoriedade de reserva de um terço dos assentos em todos os conselhos do Panchayat, assim como um terço das posições de Pradhan, exclusivamente para mulheres.

$\mathrm{Na}$ verdade, o sistema de cotas eleitorais indiano é ainda mais complexo, envolvendo também cotas (assentos nos conselhos e posições de Pradhan) para as duas minorias em desvantagem: sistemas de castas e tribos agendadas (scheduled castes and schedule tribes, em inglês). Os estados indianos foram se adaptando às novas regras eleitorais ao longo dos anos que seguiram à $73^{\mathrm{a}}$ emenda, de modo que as reservas políticas encontram-se hoje operacionais em todos os grandes estados indianos.

Um aspecto fundamental da política de reservas eleitorais no Panchayat diz respeito à aleatoriedade na reserva de assentos dos conselhos. A regra de reserva requer que, anteriormente a uma eleição, todos os GPS em um distrito sejam aleatoriamente classificados em três listas: reservados para castas agendadas, reservados para tribos agendadas, e não reservados. Dentro de cada lista, atribuem-se números de série aos GPs. Estas listas são refeitas a cada eleição para garantir que não haja reserva seguida em duas eleições para castas e tribos agendadas em nenhum GP.

A regra específica de atribuição de reservas para mulheres é diferente em cada ano eleitoral. Por exemplo, em 1998, cada terceiro GP cujo código de série começasse 
pelo número "um" deveria ser reservado para mulheres; enquanto em 2003, cada terceiro GP que começasse pelo número "dois" deveria ser reservado. Desta forma, assegura-se aleatoriedade às reservas para mulheres, com estratificação implícita para castas, tribos e quarteirões (cada número de série começa com um indicador para o quarteirão a que pertence). Abre-se ainda a possibilidade de múltiplas reservas sequenciais para mulheres, assim como a possibilidade de que alguns GPs não sejam reservados em diversas eleições consecutivas (CHATTOPADHYAY e DUFLO, 2004).

\section{Racionalidade econômica das reservas políticas no Panchayat}

Três condições são necessárias para que a política de reservas eleitorais para mulheres possa alterar o equilíbrio político-econômico de modo favorável: i) preferências entre habitantes masculinos e femininos de vilarejos devem diferir; ii) características de políticos devem importar; e iii) mulheres devem estar subrepresentadas na ausência de reservas.

Uma família cujos membros conseguem se comprometer a um padrão de votação deveria votar de modo a maximizar o valor esperado do conjunto de políticas públicas escolhidas pela família como um todo. Nestas condições, não haveria diferença entre as preferências reveladas por políticas de homens e mulheres (casados). Entretanto, Duflo e Udry (2004) apresentam indícios que sugerem que famílias dificilmente se comportam de forma eficiente, não sendo capazes de comprometer-se com padrões de votação.

Chattopadhyay e Duflo (2004), analisando as queixas formais realizadas por homens e mulheres aos Pradhans, em dois estados indianos, perceberam uma clara distinção entre preferências por bens públicos: mulheres estavam relativamente mais preocupadas com questões envolvendo água potável, enquanto homens estavam relativamente mais preocupados com questões de educação, por exemplo. Em relação ao tipo de bem público disponibilizado na presença de reservas políticas para mulheres, encontraram ainda que Pradhans femininos tendem a prover bens de modo mais similar ao que se estipulou como preferências das mulheres locais (ou preferências próprias). 
Estes resultados indicam que a reserva política para mulheres é, de fato, capaz de favorecer o grupo beneficiado pelo sistema de cotas. Entretanto, há a possibilidade de que o sistema de cotas esteja estabelecendo um ciclo de provisão de bens públicos em que mulheres tendem a extrair o máximo de bem-estar enquanto estão sob o efeito das reservas, mas ainda com a possibilidade de retorno a níveis de provisão ainda menores do que os anteriores às cotas quando estas forem retiradas (BHAVNANI, 2009).

Quanto à sub-representatividade de mulheres na ausência de cotas, e considerando que todos os habitantes indianos alfabetizados possuem igualmente direito a candidatar-se e a votar, percebe-se que na prática pouquíssimas mulheres se candidatam e, quando o fazem, dificilmente são eleitas sem a presença das reservas. De acordo com os resultados eleitorais de 2008, nos GPs não reservados para mulheres nos estados de Bengala Ocidental e Rajastão, apenas 6,5\% e 1,7\% dos Pradhans são do sexo feminino, respectivamente.

Parte desta situação de sub-representatividade ocorre, provavelmente, devido à relutância verificada por mulheres Pradhans em concorrer em eleições não reservadas (33\% afirmam não ter interesse). Nas áreas mais rurais da Índia, mulheres alfabetizadas (que podem concorrer em eleições) vivem em ambientes de classe média, nos quais ainda é visto com maus olhos o fato de mulheres trabalharem fora de casa. Um outro importante fator apontado é a baixa aceitação de mulheres por partidos políticos caso não haja obrigatoriedade, apesar de $26 \%$ das mulheres estarem dispostas a concorrerem em eleições não reservadas caso seus partidos as convidem (BEAMAN et al, 2009; BEAMAN et al., 2012).

O conjunto de crenças dos eleitores também é crucial para a compreensão da sub-representatividade feminina. As condições socioculturais que priorizam o papel doméstico das mulheres, somadas ao histórico de baixa exposição dos eleitores a lideranças femininas, podem culminar em vieses eleitorais anti lideranças femininas que dificultam ainda mais a participação política deste grupo na ausência de reservas.

A evidência empírica tende a comprovar a existência de vieses contra mulheres (de fato, contra minorias em geral). Em seu interessante estudo a respeito da seleção de músicos, Goldin e Rouse (2000) percebem que a avaliação de candidatas mulheres é substancialmente e estatisticamente maior quando a audição é conduzida às cegas, isto é, quando os jurados não são capazes de distinguir qual o gênero dos candidatos que estão se apresentando. 
No contexto político indiano, também há evidências de que existam profundos vieses políticos anti mulheres. No entanto, Beaman et al (2009), por meio de dados coletados por questionários em todos os 165 GPs do distrito de Birbhum, no estado de Bengala Ocidental, mostraram que exposição continuada à liderança feminina é capaz de reduzir vieses eleitorais de gênero.

Relativamente a Pradhans em conselhos que nunca foram reservados, Pradhans femininos em GPs reservados pela primeira vez tendem a ser pior avaliados, tudo mais constante. Contudo, quando há continuidade da exposição, por meio de uma segunda reserva consecutiva, a avaliação melhora significativamente mais do que compensando a degradação relativa à primeira exposição. Tal melhora é o principal fator apontado como mecanismo por detrás dos resultados que evidenciam maior participação e chance de eleição de mulheres em GPs com histórico de reserva nas duas eleições anteriores, independentemente do estado de reserva política subsequente.

Apesar de os resultados obtidos também serem condizentes com a hipótese de que maior participação e chances de eleição para mulheres resultam de mudanças na seleção ou comportamento de lideres femininas ao longo do tempo, os autores não encontram evidência de que características observáveis ou ações durante seus mandatos sob reserva possam justificar os resultados obtidos. As características e comportamentos médios de Pradhans femininos são dificilmente diferenciáveis, independentemente do histórico de reservas políticas do GP em eleições passadas.

Prosseguindo à análise de vieses, habitantes de vilarejos foram questionados sobre a efetividade de líderes hipotéticos por meio de vinhetas e discursos gravados, de modo que a única variação era a manipulação do gênero do líder hipotético. Em cada um dos vilarejos, cerca de metade dos entrevistados foi submetido a líderes hipotéticos masculinos e a outra metade, a líderes hipotéticos femininos.

Os resultados encontrados mostram que a exposição prévia a lideranças femininas, por meio das reservas políticas, é capaz de alterar significativamente a percepção dos habitantes masculinos a respeito da efetividade de líderes femininos. Homens que vivem em GPs nunca reservados julgaram os líderes hipotéticos como melhores quando o gênero do líder hipotético era experimentalmente manipulado para ser masculino (comparativamente à manipulação para líderes do gênero oposto).

Em contrapartida, para homens habitantes de GPs que já foram reservados em ao menos uma das duas eleições anteriores, a diferença de avaliação praticamente desaparece. Habitantes femininas, no entanto, não parecem ter seu viés inicial 
(estatisticamente indiferente de zero) alterado pelo histórico de reserva para mulheres no GP em que vivem.

A aparente falta de envolvimento com questões políticas locais pode ajudar a explicar a falta de efeitos das reservas políticas sobre o viés anti lideranças femininas exibido pelas mulheres. Baseado na capacidade do respondente em mencionar corretamente o nome do atual Pradhan, verificou-se que há duas vezes mais chances de um habitante homem satisfazer à condição do que uma mulher.

Foram conduzidos ainda uma série de testes de associação implícita (IAT, do inglês Implicit Association Tests), nos quais se testa o quão forte os respondentes associam mentalmente determinados conceitos. As associações propostas foram homem/mulher com atividades de liderança/trabalho doméstico, e homem/mulher com conceitos de bom/ruim.

Novamente, os resultados mostraram que a exposição à lideranças femininas, por meio de reservas políticas em eleições passadas, aumentou a probabilidade de que mulheres fossem associadas a atividades de liderança ao invés de trabalhos domésticos. A associação com conceitos de bom/ruim, assim como o desgosto explícito (tanto em homens quanto em mulheres) por líderes femininas, não parecem ser alterados por exposição prévia.

Combinados, os resultados expostos indicam que há fortes barreiras à entrada de mulheres no cenário político do Panchayat, reforçando o argumento de subrepresentatividade necessário para a justificação da política de cotas de gênero.

Vale ressaltar que políticas de cotas de gênero restringem forçosamente o conjunto de escolhas dos eleitores, de modo que é de crucial importância analisar a possibilidade de distorções e seus potencias impactos.

Considerando um contexto em que mulheres não enfrentassem qualquer barreira para se candidatar e que eleitores simplesmente selecionassem sistematicamente os melhores candidatos para o cargo, os candidatos eleitos por meio de cotas seriam, em média, qualitativamente inferiores àqueles eleitos de forma irrestrita. $\mathrm{O}$ efeito mecânico de eleitores terem que escolher candidatos de um grupo reduzido, devido à intervenção das reservas políticas, pode ainda ser reforçado devido ao contexto histórico não vantajoso das mulheres na Índia, as quais são em geral menos educadas e politicamente experientes do que os homens em situações similares (BAN e RAO, 2008). 
De fato, Chattopadhyay e Duflo (2004), utilizando dados de todos os 165 GPs do distrito de Birbhum, mostram que as mulheres eleitas por meio da política de reservas eleitorais, comparativamente aos Pradhans eleitos irrestritamente, possuem em média quase três anos a menos de educação formal e apresentam bem menos chances de terem recebido qualquer tipo de treinamento específico ou de terem qualquer experiência política prévia. Ademais, as mulheres eleitas para Pradhans, sob reservas políticas, são originárias de famílias mais pobres e vilarejos menores.

Como discutido anteriormente, contudo, não há evidências de que estas disparidades em qualificação dos candidatos, de acordo com o gênero e a forma de seleção, apresentem impactos sobre os resultados de oferta de bens públicos e qualidade da gestão dos GPs.

Uma outra possível distorção do sistema de cotas de gênero ocorreria caso a baixa participação de mulheres como candidatas no processo eleitoral, anteriormente à instauração das reservas políticas, decorresse primordialmente de desmotivação (percepção de altos custos em competir), e não de barreiras socioculturais à entrada e/ou vieses eleitorais anti lideranças femininas.

Caso o custo percebido de concorrer às eleições seja suficientemente alto para mulheres, então mesmo na ausência de competição masculina, o sistema de reservas políticas põe em risco a legitimidade do processo eleitoral (FOX e LAWLESS, 2004). Neste contexto, o sistema de cotas de gênero poderia enfraquecer a democracia dos vilarejos, criando potenciais candidatas eleitas que ocupam posições figurativas. Dados de Birbhum apontam que cerca de $43 \%$ das Pradhans mulheres afirmam receberem ajuda de seus maridos em questões relacionadas à gestão dos GPs, e outras $17 \%$ são casadas com membros do Panchayat.

Entretanto, os resultados sobre oferta de bens públicos indicam que estes tendem a beneficiar mais os grupos mais desfavorecidos quando as Pradhans são mulheres, enfraquecendo a hipótese de captura por elites resultante de um contexto em que mulheres eleitas seriam basicamente lideres figurativos (CHATTOPADHYAY e DUFLO, 2004).

De modo conjunto, a evidência empírica disponível tende a demonstrar que há razões econômicas que justificam a presença de políticas públicas destinadas a aumentar a participação política das mulheres no contexto do Panchayat. 


\section{Efeitos de spillover em políticas públicas}

Unidades de interesse que são inelegíveis para um tratamento específico muitas vezes serão afetadas indiretamente em uma grande variedade de intervenções. Calcular estes efeitos de spillover (ou efeitos de tratamento indireto, como definidos em Angelucci e De Giorgi, 2009) e entender os mecanismos que estão por detrás deles pode ser crucial para a elaboração de políticas públicas efetivas e eficientes.

Políticas públicas que determinam intervenções destinadas a elevar o bem-estar de populações locais frequentemente apresentam um grupo de interesse particular: famílias consideradas pobres são alvos centrais de intervenções como os programas de transferências condicionadas de renda (CCT, do inglês Conditional Cash Transfers), como o brasileiro Bolsa Família e o mexicano Progresa, os quais buscam proporcionar incentivos a aumentar os níveis educacionais das crianças destas famílias.

Entretanto, a população de interesse muitas vezes constitui um subconjunto da economia local, o que podemos definir grosso modo como a unidade geográfica ou instituição local na qual a população de interesse vive e atua. Neste sentido, podemos considerar vilarejos, vizinhanças, cidades, municípios, escolas, zonas eleitorais ou mesmo alguma concepção de extensão familiar como a economia local relevante.

O tratamento, derivado da intervenção resultante de uma política pública, pode também afetar a população local que não é, a priori, alvo desta política. No caso de CCTs, por exemplo, as famílias recipientes das transferências podem compartilhar esta renda diretamente com famílias inelegíveis, ou mesmo afetar incentivos locais para acumulação de capital humano ao utilizar a renda adicional na compra de bens e serviços ofertados por famílias inelegíveis (ANGELUCCI e DE GIORGI, 2009).

Similarmente, uma intervenção que melhorasse a oferta e a qualidade da água para apenas algumas residências específicas dentro de uma vizinhança provavelmente afetaria a todos os residentes, seja pela potencial valorização das propriedades locais, seja por ganhos de saúde coletiva relativos à redução de consumo de água contaminada, ou ainda por ganhos de bem-estar decorrentes da redução de conflitos locais por questões relacionadas à utilização das fontes de água comuns (DEVOTO et al., 2012).

Além disso, Devoto et al. (2012) mostram que se a intervenção contar com campanhas educativas sobre formas de acesso a linhas de crédito específicas para instalações de água encanada, a informação é disseminada de pessoa a pessoa dentro da 
comunidade, melhorando condições de uso da água também dos não tratados ao longo do tempo.

Há também que se considerar a possibilidade de que intervenções afetem negativamente as unidades inelegíveis da economia local relevante. Intervenções destinadas a eliminar pestes e parasitas danosos à produção agrícola em determinadas áreas de uma zona rural podem levar à migração dos agentes danosos para áreas não tratadas vizinhas. Do mesmo modo, políticas públicas destinadas a combater o crime em vizinhanças consideradas mais perigosas podem levar à elevação das taxas de criminalidade de vizinhanças não tratadas dentro da mesma economia local (DI TELLA e SCHARGRODSKY, 2004; YANG, 2008).

Efeitos de spillover podem ainda ser intencionais. Campanhas educativas sobre segurança no trânsito podem ser focadas em crianças em idade escolar, vislumbrando resultados de longo prazo assim como resultados de prazos mais curtos, uma vez que os indivíduos tratados podem influenciar o comportamento de seus familiares no trânsito. De modo similar, campanhas de imunização focadas em indivíduos considerados com alto risco de infecção apresentam o objetivo de reduzir as chances de contágio e, consequentemente, as taxas de infecção na população de baixo risco de infecção.

Independentemente da intencionalidade, indivíduos não participantes podem ser atingidos por intervenções resultantes de políticas públicas, e estes efeitos de spillover deveriam ser levados em consideração ao avaliar o impacto destas intervenções. Deixar de fazê-lo resultaria em estimativas viesadas dos impactos das intervenções, levando a recomendações inapropriadas de políticas públicas.

No caso de efeitos de spillover positivos, desconsiderá-los na avaliação da intervenção resultaria em dupla subestimação do efeito do tratamento: além do efeito da intervenção sobre os tratados ser subestimado, os efeitos da intervenção sobre os não tratados permanecerá desconhecido. No caso de efeitos de spillover negativos, os efeitos da intervenção sobre os tratados seriam sobre-estimados e, mais uma vez, os efeitos negativos indiretos sobre os não tratados passariam despercebidos.

Angelucci e Di Maro (2015) definem quatro tipos principais de efeitos de spillover: (i) externalidades; (ii) interações sociais; (iii) efeitos de equilíbrio contextual; e (iv) efeitos de equilíbrio geral. Externalidades operam a partir dos indivíduos tratados em direção à população não tratada. Miguel e Kremer (2004) constatam, por meio de uma abordagem espacial, que a utilização de medicamentos anti-helmínticos (indicados para tratamento de vermes intestinais) por crianças em idade escolar apresenta tanto 
efeitos diretos como indiretos sobre rendimento escolar, visto que a redução nas taxas de transmissão de doenças parasitárias reduz as taxas de infecção tanto de crianças tratadas quanto de não tratadas.

Efeitos de interações sociais referem-se a situações em que não tratados podem ser afetados indiretamente por intervenções por meio das relações sociais e econômicas que mantém com os indivíduos tratados. No contexto do PROGRESA, Bobonis e Finan (2009) verificaram que, em comunidades tratadas pelo programa de transferência condicional de renda, há um aumento nas matrículas do ensino secundário também de crianças pertencentes a famílias inelegíveis. Este efeito de spillover foi mais forte sobre crianças de famílias inelegíveis que apresentavam nível de pobreza superior ao da média local.

O principal mecanismo reportado por detrás da propagação dos efeitos do programa de transferência de renda, de elegíveis tratados para inelegíveis, atua por meio de peer effects locais: campanhas educativas que visam a reduzir o problema informacional de subestimação dos retornos educacionais por famílias mais pobres apresentam grandes chances de serem difundidas também às famílias inelegíveis. Como destaca Lehmann (2010, p.2), "[a]través de interações sociais (redes de famílias estendidas, igrejas, mercados, festas e outros), essa informação provavelmente chegará às famílias inelegíveis, provocando mudanças comportamentais nos investimentos em capital humano".

No caso de efeitos de equilíbrio contextual, esses efeitos de spillover resultam de uma intervenção que afeta as normas comportamentais e sociais dentro dos contextos (por exemplo, uma determinada localidade) em que estas relações são relevantes. Avitabile (2012) mostra que aumentar exogenamente a taxa de triagem médica para câncer cervical (mais conhecido por câncer do colo do útero), dentre as mulheres elegíveis em zonas rurais do México, aumenta também a quantidade de mulheres inelegíveis que passam pelas mesmas triagens. $\mathrm{O}$ principal mecanismo relatado é que o aumento exógeno leva a uma alteração da norma social até então vigente, pela qual mulheres eram constrangidas por seus maridos de serem avaliadas por médicos do sexo masculino.

Os efeitos de equilíbrio geral resultam de intervenções que afetam preços de equilíbrio através de mudanças nas ofertas e demandas relevantes. Estudar efeitos de equilíbrio geral apresenta tanto relevância econômica quanto em termos de políticas públicas. Ao nível de políticas públicas, esses estudos determinam se os efeitos de 
equilíbrio geral são capazes de contrabalancear os efeitos de equilíbrio parcial de uma intervenção. Ao nível econômico, proporcionam informações sobre as economias locais e as preferências de suas populações. Tais efeitos aparecem naturalmente em análises sobre intervenções ativas em mercados de trabalho (HECKMAN et. al, 1999), assim como podem estar presentes em CCTs (ANGELUCCI e DE GIORGI, 2009; LEHMANN, 2013).

\subsection{Efeitos de spillover em experimentos randomizados ${ }^{2}$}

Considerar a possibilidade de que efeitos de spillover estejam presentes é fundamental para a correta identificação e estimação dos efeitos de tratamento direto (ou intencional) e indireto (ou não intencional). Mensurar esses dois efeitos abre espaço para formulação de políticas públicas mais efetivas, além de melhorar a compreensão a respeito de características das economias locais e do comportamento humano.

Inicialmente, consideremos um grupo de unidades de interesse (indivíduos, famílias, vilarejos etc.) que pertencem a áreas em que o tratamento é oferecido $(T=1)$ ou não $(T=0)$. Nas áreas $(T=1)$, algumas das unidades de interesse são elegíveis para o tratamento $(E=1)$, ao passo que algumas outras não são $(E=0)$. As variáveis de interesse, $Y_{1}$ e $Y_{0}$ representam potenciais resultados na presença e na ausência de efeitos de tratamento, respectivamente. O efeito médio de tratamento sobre os elegíveis (ATE, do inglês Average Treatment Effect) é representado pelo efeito do tratamento sobre as unidades de interesse que deveriam ser supostamente tratadas. Formalmente:

$$
A T E=\mathrm{E}\left(\mathrm{Y}_{1}-\mathrm{Y}_{0} \mid \mathrm{T}=1, \mathrm{E}=1\right)
$$

Embora o resultado na presença do tratamento seja o resultado observado para as unidades de interesse elegíveis na área tratada, $\mathrm{E}\left(\mathrm{Y}_{1} \mid \mathrm{T}=1, \mathrm{E}=1\right)=\mathrm{E}(\mathrm{Y} \mid \mathrm{T}=1, \mathrm{E}=1)$, $\mathrm{o}$ resultado potencial na ausência do tratamento, $\mathrm{E}\left(\mathrm{Y}_{0} \mid \mathrm{T}=1, \mathrm{E}=1\right)$, é desconhecido. A falta deste contrafatual pode ser resolvida se as seguintes duas hipóteses se mantiverem verdadeiras: (i) a atribuição do tratamento é independente dos resultados; e (ii) a qualidade de tratado de uma determinada unidade de interesse não afeta os potenciais resultados de outras unidades de interesse. Chama-se a primeira de "hipótese de ignorabilidade forte" (ou unconfoundedness assumption, em inglês); e a segunda de

\footnotetext{
${ }^{2}$ Esta seção segue a apresentação da abordagem de efeitos de spillover apresentada em Angelucci e De Giorgi (2009) e Angelucci e Di Maro (2015).
} 
"hipótese do valor de tratamento unitário estável" (SUTVA, do inglês Stable Unit Treatment Value Assumption).

A aleatoriedade da elegibilidade é suficiente para garantir que a hipótese de ignorabilidade seja mantida, de modo que, ausentes efeitos de spillover em áreas $(T=1)$, tenhamos $\mathrm{E}\left(\mathrm{Y}_{0} \mid \mathrm{T}=1, \mathrm{E}=1\right)=\mathrm{E}(\mathrm{Y} \mid \mathrm{T}=1, \mathrm{E}=0)$. A presença de spillovers, no entanto, é suficiente para violar a hipótese SUTVA, fazendo com que o resultado médio observado para as unidades inelegíveis da área $(T=1)$ não seja igual ao resultado potencial médio na ausência do tratamento.

Estratégias de dupla randomização podem ser utilizadas para contornar a falta de contrafatuais na presença de efeitos de spillover. A ideia da dupla randomização é primeiramente identificar a economia local relevante e, posteriormente, atribuir de forma aleatória unidades para os grupos de tratamento $(T=1)$ e controle $(T=0)$. Por fim, atribui-se a elegibilidade $(E=1)$ aleatoriamente em ambos os grupos.

Esta abordagem resulta em três grupos distintos delimitados por tratamento e elegibilidade: unidades de interesse elegíveis e inelegíveis dentro do grupo de tratamento e unidades de interesse pertencentes ao grupo de controle. Na ausência de efeitos de spillover partindo do grupo de tratamento em direção ao grupo de controle, ambas as hipóteses de ignorabilidade forte e SUTVA seriam respeitadas pelas unidades de interesse do grupo de controle. Deste modo, o ATE seria definido por:

$$
A T E=\mathrm{E}\left(\mathrm{Y}_{1}-\mathrm{Y}_{0} \mid \mathrm{T}=1, \mathrm{E}=1\right)=\mathrm{E}(\mathrm{Y} \mid \mathrm{T}=1, \mathrm{E}=1)-\mathrm{E}(\mathrm{Y} \mid \mathrm{T}=0)
$$

Esta abordagem permite a mensuração dos efeitos de spillover por meio de um efeito de tratamento indireto (ITE, do inglês Indirect Treatment Effect), definido como o efeito médio do tratamento sobre as unidades de interesse inelegíveis. O ITE pode ser calculado como:

$$
I T E=\mathrm{E}\left(\mathrm{Y}_{1}-\mathrm{Y}_{0} \mid \mathrm{T}=1, \mathrm{E}=0\right)=\mathrm{E}(\mathrm{Y} \mid \mathrm{T}=1, \mathrm{E}=0)-\mathrm{E}(\mathrm{Y} \mid \mathrm{T}=0)
$$

Apesar de resolver o problema de ausência de contrafatual para a estimação dos parâmetros ATE e ITE, vale ressaltar que nesta abordagem a hipótese SUTVA ainda pode ser violada dentro do grupo de tratamento. Pode-se pensar no ATE estimado como a combinação do ATE verdadeiro (ATE se SUTVA fosse válido também no grupo de tratamento) com o efeito de spillover, ambos parâmetros dependentes da 
parcela de tratados. Angelucci e De Girogi (2009) ressaltam que se os efeitos de spillover forem uma função da parcela de tratados da economia local, o ATE estimado irá variar à medida que a escala da intervenção for ampliada.

O efeito médio total do tratamento (TATE, do inglês Total Average Treatment Effect) seria portanto uma média ponderada do ATE e do ITE, cujos pesos (wATE e wITE) representam, respectivamente, a proporção amostral dos grupos $(E=1) \mathrm{e}$ $(E=0)$. Formalmente:

$$
T A T E={ }_{w A T E} A T E+{ }_{w I T E} I T E
$$

No caso de suspeita de violação da SUTVA também no grupo de tratamento, isto é, unidades de interesse tratadas elegíveis afetando potenciais resultados de outras unidades não tratadas; podemos ainda dispor da metodologia apresentada em Miguel e Kremer (2004), no qual os autores fazem uso de uma estratégia baseada em densidades locais de tratados para verificar os efeitos de spillover. Em termos lineares, podemos estimar efeitos de tratamento na presença de spillovers por:

$$
Y_{i}=\alpha+\beta_{1} T_{i}+\gamma_{d} N_{d i}^{T}+\varphi_{d} N_{d i}+\delta X_{i}^{\prime}+\mu_{i}+\epsilon_{i}
$$

Em que $Y_{i}$ representa o resultado analisado para a unidade de interesse i; $T_{i}$ é uma dummy que assume valor 1 no caso da unidade i ter recebido tratamento e 0 , caso contrário; $X_{i}^{\prime}$ representa o vetor de variáveis de controle para unidades de interesse i. As variáveis $N_{d i}^{T}$ e $N_{d i}$, assim como seus parâmetros $\gamma_{d}$ e $\varphi_{d}$, funcionam como captadores dos efeitos de spillover do tratamento. $N_{d i}$ representa a quantidade total de unidades de interesse a uma distância d da unidade $\mathrm{i}$; ao passo que $N_{d i}^{T}$ representa a quantidade de unidade tratadas a uma distância d da unidade i, isto é representa a densidade local de tratados para cada unidade $\mathrm{i}$.

A validade do método acima depende da suposição de que, dado o número total de unidades de interesse nas proximidades de uma unidade específica i, o número de unidades que receberam tratamento dentro da mesma distância deve ser exógeno e aleatório. Considerando que qualquer efeito independente da densidade local seja capturado pelos termos $N_{d i}$, os coeficientes $\gamma_{d}$ mensuram o efeito de spillover do tratamento entre unidades de interesse. Neste arcabouço, $\beta_{1}+\gamma_{d} \overline{N_{d l}^{T}}$ representa o efeito 
médio de tratamento sobre o resultado de interesse $Y_{i}$, e $\overline{N_{d l}^{T}}$ representa o número médio de unidades tratadas dentro de um raio d da unidade de interesse $\mathrm{i}$.

\subsection{Potenciais efeitos de spillover no sistema de reservas políticas indiano}

O sistema de reservas políticas para mulheres no Panchayat e sua execução randomizada, repetida diversas vezes em eleições consecutivas; combinado ao fato de que os GPs representam grupos de vilarejos rurais, justapostos ao longo do território indiano, dificultam a separação geográfica de unidades tratadas de não tratadas.

A possibilidade de que os habitantes de vilarejos geograficamente próximos possivelmente vizinhos, embora pertencentes a distintos GPs justapostos - mantenham entre si relações comerciais e sociais não é desprezível. As pessoas com as quais interagimos de forma regular, e até mesmo algumas com as quais interagimos apenas esporadicamente, são capazes de influenciar nossas crenças, decisões e comportamentos. São vários os exemplos dos efeitos das redes sociais sobre atividade econômica: transmissão de informações a respeito de empregos, novos produtos, tecnologias e opiniões políticas (JACKSON, 2011).

Utilizando dados sobre 43 vilarejos rurais no sul da Índia, Banerjee et al. (2013) verificam de que modo a informação acerca das condições para participação em um programa de microcrédito é difundida por meio das redes sociais existentes entre os habitantes dos vilarejos. Os resultados obtidos demonstram que o nível de compartilhamento de informações é bastante ativo entre estes vilarejos.

Estimam que um indivíduo que esteja participando do programa de microcrédito apresente cerca de sete vezes mais probabilidade de compartilhar informações sobre o programa com demais habitantes do vilarejo, quando comparado a um não participante. Entretanto, o montante de informação transmitida por não participantes também é bastante significativo, correspondendo a cerca de um terço do total, pois o número de não participantes é muito maior. Os vilarejos que apresentam maiores taxas de difusão informacional são aqueles em que os habitantes em papeis centrais enquanto difusores de informação (professores, líderes comunitários, donos de estabelecimentos comerciais etc.) são os primeiros a serem informados do programa de microcrédito.

Dado o exposto, parece bastante razoável desconsiderar a hipótese de que GPs apresentem economias e sociedades locais suficientemente isoladas umas das outras, de modo a supor que a condição SUTVA fosse respeitada. Análises sobre os efeitos 
resultantes da intervenção randomizada de cotas de gênero deveriam, portanto, considerar a possibilidade de efeitos de spillover de tratados para não tratados.

Os efeitos da exposição continuada a lideranças femininas sobre as taxas de participação e probabilidade de eleição de mulheres em eleições irrestritas é de especial relevância no contexto de efeitos de spillover, haja vista que a difusão de informações sobre experiências e opiniões políticas - incrivelmente relevantes no contexto de redes sociais - a respeito de líderes femininas é apontada como um dos principais mecanismos de inserção política de longo prazo para as mulheres em Beaman et al. (2009).

Considerando o mecanismo de redução de vieses como fundamental à maior inserção política de mulheres nos GPs, a presença de spillovers positivos sobre a redução de vieses políticos em GPs que nunca foram reservados, devido a sua proximidade com outros GPs com histórico de reserva, aceleraria o processo e garantiria que os resultados fossem mais generalizados, uma vez que não seria necessário contar com a sorte de ser sorteado para reservas (talvez diversas vezes consecutivas) para que se percebam resultados.

Por outro lado, possíveis efeitos de spillover negativos poderiam estar reduzindo o impacto estimado das reservas políticas sobre a redução de vieses eleitorais contra lideranças femininas. Neste caso, a forma de aplicação da aleatoriedade do sistema de cotas, assim como sua duração e abrangência podem acabar não sendo tão eficazes, visto que há possibilidades de que a disparidade entre a participação política feminina em GPs diferentes venha a aumentar.

GPs frequentemente sorteados contariam com vieses reduzidos, uma vez que o efeito positivo direto das reservas mais do que compensaria o potencial efeito negativo resultante dos spillovers negativos de GPs tratados vizinhos. Mas, por outro lado, GPs que não sejam sorteados frequentemente (ou mesmo nunca sorteados) arcariam com vieses progressivamente maiores à medida que seus vizinhos fossem continuamente sorteados para as reservas.

No caso de efeitos nulos de spillover, a eficácia direta da política de reservas eleitorais é mantida, assim como apresentado em Beaman et al. (2009); embora permaneçam relevantes as considerações sobre a necessidade de que as cotas sejam mantidas por tempo suficiente até que boa parte dos GPs sejam reservados de forma consecutiva e possam, enfim, ser verificadas reduções nos vieses eleitorais e consequentes melhorias nas condições políticas femininas de forma abrangente. 
A consideração de possíveis spillovers apresenta também um papel metodológico importante, uma vez que resultados obtidos podem estar sendo estimados com baixa precisão devido a vieses resultantes da omissão de potenciais termos de spillovers. Mesmo que não sejam individualmente significantes, variáveis que tentem captar efeitos de spillover podem mesmo assim contribuir para maior capacidade explicativa do modelo de forma conjunta, melhorando as estimativas de outras potenciais variáveis relevantes.

\section{Estratégia empírica}

\section{$5.1 \quad$ Base de dados}

De modo a verificar se existem efeitos de spillover sobre a participação política de mulheres em eleições irrestritas e sobre o viés eleitoral anti lideranças femininas, faço uso da base de dados originalmente utilizada e disponibilizada por Beaman et al. (2009). Esta base de dados contém informações referentes aos 165 GPs localizados no distrito de Birbhum, no estado indiano de Bengala Ocidental.

Dentre os principais dados disponíveis, constam informações a respeito do histórico de reserva de cada GP nas eleições de 1998 (primeira eleição com presença de reservas políticas para mulheres no estado), 2003 e 2008, assim como seus respectivos resultados eleitorais. Anteriormente às eleições de 2008, aproximadamente $45 \%$ dos GPs (74 GPs) nunca haviam sido reservados, 43\% foram reservados uma única vez (36 em 1998, e 35 em 2003), e 12\% foram reservados duas vezes consecutivas (20 GPs com reserva em ambas as eleições de 1998 e 2003).

Os dados contém ainda respostas de questionários foram aplicados a todos os Pradhans eleitos nas eleições de 1998 e 2003, a respeito das condições socioeconômicas de suas familias. Por fim, estão disponíveis também dados experimentais e de questionários aplicados a habitantes de três vilarejos, escolhidos aleatoriamente, em cada GP (totalizando 495 vilarejos selecionados ao todo), a respeito de condições socioeconômicas e opinião política.

Para a aplicação do método de avaliação de spillovers locais desenvolvido em Miguel e Kremer (2004), diversas variáveis de densidade de tratamento foram construídas e adicionadas à base de dados original. Inicialmente obtive informações 
geográficas sobre cada um dos GPs, de modo a construir uma tabela de distâncias geodésicas com base em suas posições centrais mapeadas em latitude e longitude.

Por se tratarem de localidades rurais, relativamente pequenas e de modestas populações, não foi possível obter informações geográficas precisas a respeito das fronteiras e/ou sobre distribuição populacional ao longo de cada GP. Tais informações teriam sido úteis para testes com efeitos de spillover para GPs com contato direto de fronteiras.

A priori apenas os nomes dos GPs e seus respectivos "quarteirões" estavam disponíveis na base de dados original. A utilização direta destas informações em serviços de busca de localizações (como o Google Maps), no entanto, não se mostrou suficiente para obter as informações de latitude e longitude necessárias à análise empírica deste trabalho. Dificilmente a busca por nome de um dado GP, mesmo acompanhado de informação a respeito de seu "quarteirão", resultaria em informação geográfica precisa a respeito de sua localização: diversas instituições (escolas, hospitais, centros comunitários etc.), assim como vilarejos parecem compartilhar dos mesmos nomes ao longo do território indiano. Além disso, diversas entradas da base de dados simplesmente não resultam em nenhum resultado de localização.

De modo a contornar este problema, após frutífero contato com o Departamento de Panchayats e Desenvolvimento Rural do Governo de Bengala Ocidental, recebi informação adicional a respeito dos códigos postais utilizados como referência para o recebimento de correspondência pelas administrações dos conselhos de cada GP do distrito de Birbhum ${ }^{3}$. De posse dos nomes dos GPs, informação sobre o "quarteirão" a que pertencem e código postal, tornou-se possível encontrar as localizações das administrações de cada GP.

Deste modo, a informação geográfica que foi efetivamente obtida corresponde às coordenadas geográficas referentes ao endereço postal das administrações dos conselhos de cada GP. Como a metodologia de análise de Miguel e Kremer (2004) utiliza variáveis de contagem baseadas no número de observações dentro de determinados raios em relação aos pontos de referência geográfica utilizados para cada observação, seria preferível que o ponto de referência estivesse localizado de forma o mais centralizada possível dentro da área de cada GP.

\footnotetext{
${ }^{3}$ Agradeço à atenção e boa vontade apresentados pelo Departamento de Panchayats e Desenvolvimento Rural, do Governo de Bengala Ocidental, para a realização desta etapa do plano de trabalho. As orientações e informações obtidas, por meio de troca de emails ao longo de alguns meses, foram indispensáveis para a obtenção das localizações geográficas dos GPs de Birbhum.
} 
Ao utilizar como referência endereços postais é provável que as distâncias estimadas entre os GPs apresentem pequenas perturbações, reforçando a necessidade de checar a robustez das especificações com maior número de raios. De posse destes dados, tornou-se possível construir uma matriz de distâncias geodésicas entre todos os pares de municípios analisados.

As variáveis de densidade local de tratados e densidade total são basicamente variáveis de contagem: densidade total indica quantos GPs situam-se a uma distância menor ou igual a d para cada GP da amostra; e a densidade local de tratados indica quantos GPs com histórico de reservas políticas para mulheres situam-se a uma distância menor ou igual a d para cada GP.

Foram escolhidos 22 raios diferentes de modo que representassem percentis usuais em análise estatística e conferissem robustez ao método empregado (Tabela 1).

\section{TABELA 1}

Relação de raios e percentis

\begin{tabular}{cccccccccccc}
\hline \hline Raio (km) & 6 & 9 & 15 & 20 & 24 & 27 & 31 & 35 & 38 & 41 & 44 \\
Percentil & $1 \%$ & $2 \%$ & $5 \%$ & $10 \%$ & $15 \%$ & $20 \%$ & $25 \%$ & $30 \%$ & $35 \%$ & $40 \%$ & $45 \%$ \\
& & & & & & & & & & & \\
Raio (km) & 48 & 51 & 54 & 57 & 61 & 65 & 71 & 76 & 82 & 91 & 198 \\
Percentil & $50 \%$ & $55 \%$ & $60 \%$ & $65 \%$ & $70 \%$ & $75 \%$ & $80 \%$ & $85 \%$ & $90 \%$ & $95 \%$ & $99 \%$ \\
\hline \hline
\end{tabular}

Notas: A interpretação de cada raio é a seguinte: situam-se em um raio d, de um GP representativo, em média $X \%$ dos outros GPs pertencentes à amostra. Por exemplo, em um raio de $15 \mathrm{~km}$, um GP representativo possui em média 5\% das observações (cerca de 8 GPs) ao seu redor; em um raio de $38 \mathrm{~km}$, seriam $35 \%$ das observações (cerca de 58 GPs) ao seu redor.

Apesar de não possuir informação precisa a respeito da área de cada GP da amostra, as áreas do distrito de Birbhum e de seus quarteirões são facilmente encontradas (figura 1), possibilitando-se realizar algumas inferências a respeito dos raios mais relevantes para captar distâncias efetivas de interação entre GPs vizinhos dentro de um mesmo quarteirão, assim como interações de GPs representativos pertencentes a quarteirões vizinhos. 


\section{FIGURA 1}

Mapa oficial do distrito de Birbhum, Bengala Ocidental, Índia

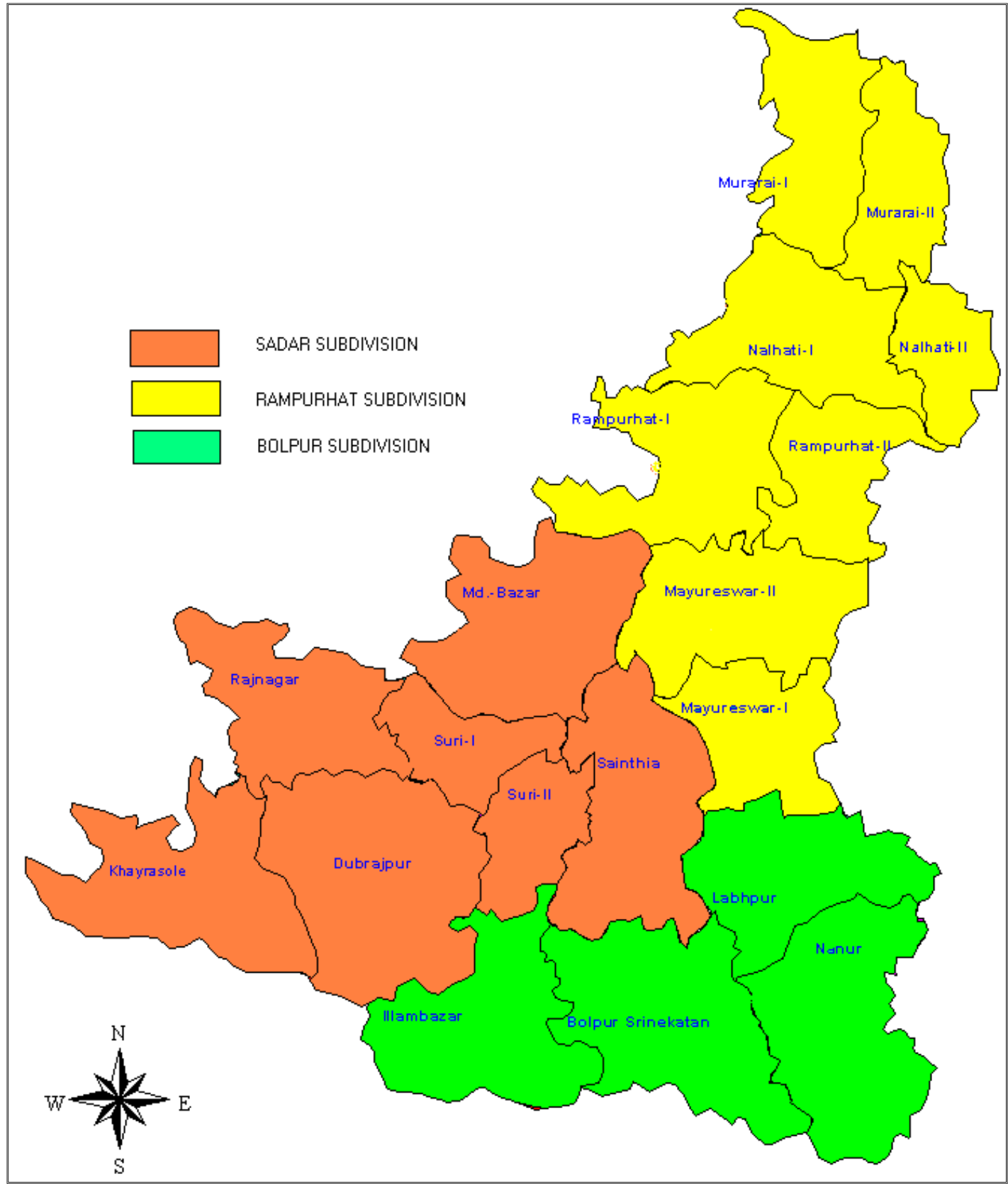

Notas: Mapa oficial do distrito de Birbhum, com informações a respeito de suas três subdivisões (Sadar, Rampurhat e Bolpur) assim como os 19 quarteirões que o compõem. Obtido por meio do endereço eletrônico http://birbhum.gov.in/distmap.htm, acessado em 15/11/2015.

A área total do distrito de Birbhum é de $4545 \mathrm{~km}^{2}$, divididos entre 19 quarteirões e 165 GPs. De modo a obter aproximações sobre a área de cada GP, podemos assumir que os 165 GPs correspondam à totalidade da área do distrito de Birbhum, que apresentem todos a mesma área e que possam ser aproximados por 
quadrados. Deste modo, teríamos GPs representativos com cerca de 27,54 km² de área, os quais poderiam ser inscritos em circunferências cujos raios seriam equivalentes à metade de sua diagonal, isto é, cerca de $3,71 \mathrm{~km}$. Procedendo de maneira similar, cada quarteirão representativo apresentaria $239,21 \mathrm{~km}^{2}$ de área, o que os levaria a serem circunscritos por circunferências com raios de $10,93 \mathrm{~km}$.

As suposições utilizadas para a obtenção das aproximações de áreas e raios de cobertura acima são bastante fortes e provavelmente irrealistas. Servem, entretanto, como orientação para a análise dos resultados em função dos raios utilizados: os pontos centrais de dois GPs representativos vizinhos estão distantes em cerca de 7,42 km; similarmente, dois GPs representativos pertencentes à quarteirões vizinhos apresentam cerca de $21,87 \mathrm{~km}$ entre seus pontos centrais.

Considerando que a distância entre os pontos centrais corresponda ao potencial espaço de interação entre os GPs, os raios entre 6 e $9 \mathrm{~km}$ podem ser vistos como os que melhor captam possíveis efeitos de spillover entre fronteiras de GPs vizinhos; ao passo que os raios entre 20 e $24 \mathrm{~km}$ representem relações de GPs de um dado quarteirão para com o quarteirão vizinho.

\subsection{Efeitos intertemporais de reservas políticas}

De modo a investigar a presença de efeitos de spillovers decorrentes das reservas políticas, as principais regressões apresentadas em Beaman et al. (2009) são reestimadas, acrescentado-se as variáveis de densidade total e densidades locais de tratados como sugerido por Miguel e Kremer (2004).

Vale ressaltar que é graças à aleatoriedade do processo de reservas políticas para mulheres que se torna possível analisar seus efeitos de forma reduzida, por meio de comparação dos resultados médios de interesse em distintos GPs com diferentes condições de reservas políticas.

Para verificar se de fato há efeitos de reservas passadas sobre os resultados políticos obtidos por candidatas femininas em eleições irrestritas para assentos nos conselhos dos GPs, assim como possíveis efeitos de spillover, estimam-se regressões como as representadas pela equação 6. Por falta de informações geográficas a respeito de todos os GPs, pertencentes a 6 diferentes estados indianos, utilizados por Beaman et 
al. (2009) nas regressões para resultados eleitorais para Pradhans, restringe-se a análise apenas aos assentos dos conselhos dos GPs ${ }^{4}$.

$$
\begin{aligned}
Y_{i g j} & =\beta_{2} R_{g 2}+\beta_{2 e_{1} R_{g, 2 e 1}+\beta_{1} R_{g 1}} \\
& +\gamma_{2 d} N_{d g 2}^{T}+\gamma_{d, 2 e{ }_{1}} N_{d g, 2 e 1}^{T}+\gamma_{1 d} N_{d g 1}^{T}+\varphi_{d} N_{d g}+\alpha_{j}+\epsilon_{i g}
\end{aligned}
$$

A variável dependente, $Y_{i g j}$, é uma dummy que indica se o candidato i, concorrendo a um assento do conselho do GP g, pertencente ao quarteirão irrestrito nas eleições de 2008 j, é uma mulher. Modificando a variável dependente de modo a restringi-la para que indique se o candidato i, eleito para o conselho do GP g é uma mulher, pode-se avaliar o efeito de reservas políticas passadas sobre a probabilidade de eleição de candidatas mulheres.

As variáveis $R_{g 1}$ e $R_{g 2}$ são dummys que indicam se o GP g foi reservado exclusivamente no primeiro ou no segundo ciclo eleitoral, isto é, apenas em 1998 ou apenas em 2003, respectivamente. Por sua vez, $R_{g 2} e_{1}$, é um indicador para os GPs que foram reservados consecutivamente nos dois últimos ciclos eleitorais (em 1998 e 2003).

Similarmente, $N_{d g 1}^{T}$ e $N_{d g 2}^{T}$, representam as variáveis de densidades locais de tratados exclusivamente em 1998 ou exclusivamente em 2003 dentro de um raio d, respectivamente; e $N_{d g, 2 \text { e } 1}^{T}$ representa a densidade local de tratados em ambos 1998 e 2003 dentro de um raio d. $N_{d g}$ representa o número total de GPs que se situam dentro de um raio d, ao redor do GP g. Efeitos fixos referentes aos quarteirões são capturados por $\alpha_{j}$. Os erros padrões reportados são robustos e agrupados pelos GPs, uma vez que cada GP possui diversos assentos sendo disputados simultaneamente para seus conselhos. De modo a ampliar a robustez dos resultados, são estimadas regressões para todos os 22 raios apresentados na Tabela 1.

\subsubsection{Resultados}

Os resultados das regressões cuja variável dependente é a porcentagem de mulheres que se candidatam estão expressos na Tabela 2, na qual são reportados os

\footnotetext{
${ }^{4}$ Ao estimar regressões utilizando apenas os 165 GPs de Birbhum, para o qual estão disponíveis dados geográficos, a amostra disponível para as eleições de 2008 seria de exatamente 165 observações, haja visto que apenas um Pradhan é eleito em cada GP. Nestas condições, ambos resultados com e sem efeitos de spillover (estimados em regressões como expressas pela equação 6) não apresentam qualquer significância estatística.
} 
resultados originais das regressões sem controles para possíveis efeitos de spillover (coluna $0 \mathrm{~km}$ ) assim como resultados para as regressões controlando para alguns raios em ordem crescente.

Em traços gerais, a inclusão de variáveis de densidades locais de tratados não alterou significativamente os resultados quando estas não estão inclusas: ter sido reservado duas vezes consecutivas em eleições passadas apresenta impacto positivo, significante e significativo sobre a porcentagem de mulheres que se candidatam em eleições subsequentes, mesmo quando as reservas não estão mais presentes.

As variáveis de densidade locais de tratados, ao longo das diferentes especificações com raios progressivos, mostram-se estatisticamente indistinguíveis de zero. A exceção ocorre para raios nos intervalos de 38 a $41 \mathrm{~km}$ e de 76 a $82 \mathrm{~km}$. Nestes dois intervalos, as regressões apresentam o tipo de impacto esperado com a omissão de potenciais efeitos de spillover positivos: o coeficiente estimado para a variável reserva consecutiva dupla $\left(R_{g, 2} e_{1}\right)$ é maior em magnitude e mais significante.

\section{TABELA 2}

Participação feminina nas eleições para os conselhos de GPs em 2008

\begin{tabular}{|c|c|c|c|c|c|c|c|}
\hline \multirow[t]{2}{*}{$\mathrm{N}=3431$} & \multicolumn{7}{|c|}{ Candidatas concorrendo } \\
\hline & $0 \mathrm{~km}$ & $6 \mathrm{~km}$ & $15 \mathrm{~km}$ & $24 \mathrm{~km}$ & $31 \mathrm{~km}$ & $38 \mathrm{~km}$ & $44 \mathrm{~km}$ \\
\hline \multirow[t]{2}{*}{$R_{g 1}$} & $-0,009$ & $-0,016$ & $-0,006$ & $-0,021 *$ & $-0,007$ & 0,001 & $-0,002$ \\
\hline & $(0,011)$ & $(0,11)$ & $(0,013)$ & $(0,012)$ & $(0,012)$ & $(0,11)$ & $(0,011)$ \\
\hline \multirow[t]{2}{*}{$R_{g 2}$} & $-0,007$ & $-0,011$ & $-0,011$ & $-0,015$ & $-0,004$ & $-0,004$ & $-0,003$ \\
\hline & $(0,011)$ & $(0,011)$ & $(0,012)$ & $(0,014)$ & $(0,011)$ & $(0,011)$ & $(0,013)$ \\
\hline \multirow[t]{2}{*}{$R_{g 2 \text { e } 1}$} & $0,037 * * *$ & $0,037 * * *$ & $0,038 * *$ & $0,027 * *$ & $0,047 * * *$ & $0,055^{* * *}$ & $0,043 * * *$ \\
\hline & $(0,014)$ & $(0,014)$ & $(0,016)$ & $(0,015)$ & $(0,015)$ & $(0,015)$ & $(0,013)$ \\
\hline \multirow[t]{2}{*}{$N_{1 d}^{T}$} & & $-0,011 *$ & 0,002 & $-0,013 * * *$ & 0,000 & $0,010 * *$ & 0,005 \\
\hline & & $(0,006)$ & $(0,005)$ & $(0,004)$ & $(0,004)$ & $(0,002)$ & $(0,0047)$ \\
\hline \multirow[t]{2}{*}{$N_{2 d}^{T}$} & & 0,000 & $-0,008$ & $-0,008$ & 0,008 & 0,007 & 0,006 \\
\hline & & $(0,008)$ & $(0,005)$ & $(0,005)$ & $(0,005)$ & $(0,004)$ & $(0,007)$ \\
\hline \multirow[t]{2}{*}{$N_{2}^{T}$ e $1, d$} & & 0,001 & 0,000 & $-0,008$ & 0,009 & $0,013 *$ & 0,010 \\
\hline & & $(0,009)$ & $(0,005)$ & $(0,006)$ & $(0,006)$ & $(0,006)$ & $(0,007)$ \\
\hline
\end{tabular}

Notas: Todas as regressões foram estimadas por MQO, incluindo efeitos fixos de "quarteirões", erros padrões ajustados para heteroscedasticidade e agrupados em GPs.

*** significância ao nível de 1\%; ** significância ao nível de 5\%; * significância ao nível de $10 \%$. 
A pontualidade destes resultados, no entanto, frente ao maior número de evidências de ausência de efeitos de spillover - especialmente em raios menores, os quais possivelmente representam melhor o ambiente mais propício a interações sociais interfronteiras - nos leva a usar de cautela em sua interpretação e considerá-los como resultados potencialmente erráticos, resultantes de falhas na modelagem, problemas com a construção das variáveis de densidade, ou mesmo falhas no processo de randomização da distribuição de tratados naqueles intervalos específicos.

$\mathrm{Na}$ Tabela 3 estão expostos os resultados das regressões cuja variável dependente é a probabilidade de que os candidatos eleitos sejam mulheres em eleições irrestritas. Também não há evidências de efeitos de spillover afetando sistematicamente as chances de eleições de mulheres em eleições irrestritas.

\section{TABELA 3}

Probabilidade de vitória feminina nas eleições para os conselhos de GPs em 2008

\begin{tabular}{|c|c|c|c|c|c|c|c|}
\hline \multirow[t]{2}{*}{$\mathrm{N}=1191$} & \multicolumn{7}{|c|}{ Candidatas eleitas } \\
\hline & $0 \mathrm{~km}$ & $6 \mathrm{~km}$ & $15 \mathrm{~km}$ & $24 \mathrm{~km}$ & $31 \mathrm{~km}$ & $38 \mathrm{~km}$ & $44 \mathrm{~km}$ \\
\hline \multirow[t]{2}{*}{$R_{g 1}$} & 0,002 & $-0,006$ & 0,009 & $-0,015$ & 0,010 & 0,018 & 0,027 \\
\hline & $(0,019)$ & $(0,019)$ & $(0,019)$ & $(0,019)$ & $(0,018)$ & $(0,018)$ & $(0,019)$ \\
\hline \multirow[t]{2}{*}{$R_{g 2}$} & 0,000 & $-0,009$ & $-0,013$ & $-0,012$ & 0,005 & 0,005 & 0,008 \\
\hline & $(0,018)$ & $(0,018)$ & $(0,019)$ & $(0,020)$ & $(0,017)$ & $(0,018)$ & $(0,020)$ \\
\hline \multirow[t]{2}{*}{$R_{g 2 \text { e } 1}$} & $0,057 *$ & $0,057^{*}$ & 0,053 & 0,041 & $0,071 *$ & $0,080 * * *$ & $0,071 * *$ \\
\hline & $(0,032)$ & $(0,029)$ & $(0,035)$ & $(0,033)$ & $(0,032)$ & $(0,030)$ & $(0,030)$ \\
\hline \multirow[t]{2}{*}{$N_{1 d}^{T}$} & & $-0,013$ & 0,001 & $-0,018 * *$ & 0,009 & $0,017 *$ & $0,025 * * *$ \\
\hline & & $(0,013)$ & $(0,008)$ & $(0,007)$ & $(0,008)$ & $(0,009)$ & $(0,008)$ \\
\hline \multirow[t]{2}{*}{$N_{2 d}^{T}$} & & $-0,004$ & $-0,025^{* * *}$ & $-0,012$ & 0,015 & $0,017 * *$ & 0,007 \\
\hline & & $(0,013)$ & $(0,010)$ & $(0,009)$ & $(0,008)$ & $(0,007)$ & $(0,010)$ \\
\hline \multirow[t]{2}{*}{$N_{2 e 1, d}^{T}$} & & 0,008 & $-0,011$ & $-0,015$ & 0,010 & $0,018 *$ & 0,014 \\
\hline & & $(0,016)$ & $(0,009)$ & $(0,010)$ & $(0,011)$ & $(0,011)$ & $(0,011)$ \\
\hline
\end{tabular}

Notas: Todas as regressões foram estimadas por MQO, incluindo efeitos fixos de "quarteirões", erros padrões ajustados para heteroscedasticidade e agrupados em GPs.

*** significância ao nível de 1\%; ** significância ao nível de 5\%; * significância ao nível de $10 \%$. 
Os resultados originais (coluna $0 \mathrm{~km}$ ) aqui não são, no entanto, muito significativos individualmente: o p-valor do coeficiente estimado para o indicador de reserva consecutiva é de 0,075 e seu intervalo de confiança engloba o zero. Para diversos raios, mesmo com as variáveis de densidades locais permanecendo estatisticamente indiferentes de zero, percebe-se ganhos de significância para o principal indicador da regressão original.

Mais uma vez os intervalos de raios entre 38 e $41 \mathrm{~km}$ e 76 e $82 \mathrm{~km}$ apresentam os impactos esperados de estimativas quando corrigido o viés de omissão de efeitos de spillover positivos. Considerando o raio de $38 \mathrm{~km}$, por exemplo, o efeito direto de reservas consecutivas sobre as chances de eleição de uma mulher passam dos originais 5,4 pontos percentuais para 8 pontos percentuais (p-valor de 0,008 ). Pelos mesmos motivos expostos anteriormente, no entanto, a interpretação destas estimativas para estes intervalos pontuais será a de potencial resultado errático.

Conjuntamente, os resultados obtidos com as regressões do tipo da equação 6 não evidenciam qualquer efeito de spillover sistemático. Em outras palavras, apesar da verificação da existência de redes sociais funcionais e relevantes em vilarejos rurais similares aos do presente estudo, por Banerjee et al. (2013), não há evidências de que estar próximo de GPs que foram reservados uma ou duas vezes nas eleições passadas afete de alguma forma as probabilidades de eleição ou mesmo o número de candidaturas femininas em eleições irrestritas. Os efeitos diretos verificados por Beaman et al. (2009) parecem, por hora, apenas ser usufruídos por aqueles 20 GPs que por acaso foram expostos à liderança feminina obrigatória por dois mandatos consecutivos.

\subsection{Crenças de eleitores e viés eleitoral contra mulheres}

Vieses contra líderes femininas podem refletir puramente questões de gosto ou resultarem de discriminação estatística. Ambas as possibilidades podem ainda reforçar uma a outra caso a discriminação por gosto dificulte a eleição inicial de candidatas mulheres, o que, por sua vez, dificultaria ainda mais os eleitores a adquirirem informações sobre a real capacidade de lideranças femininas.

A falta de informação a respeito da competência de mulheres na posição de líderes pode, ainda, levar eleitores avessos a risco a deixarem de eleger mulheres em eleições subsequentes. O resultado é um ciclo vicioso em que mulheres dificilmente são eleitas e os vieses anti liderança feminina não são amenizados. 
Mesmo considerando que a discriminação por gosto seja profundamente enraizada em padrões socioculturais que persistem ao longo da história indiana e, consequentemente, de difícil tratamento; ao reduzir a discriminação estatística já seria possível melhorar o prospecto eleitoral para mulheres no longo prazo, uma vez que a disponibilidade de informação ao longo do tempo amenizaria os riscos de eleger mulheres sem maiores informações em relação a sua capacidade de liderança (BEAMAN et al., 2009).

No estudo original, utilizam-se questionários para verificar de que modo habitantes de vilarejos pertencentes a GPs com diferentes históricos de reservas políticas para mulheres avaliam a efetividade de líderes hipotéticos. Expostos a vinhetas e discursos idênticos, cuja única variação era a manipulação experimental do gênero do Pradhan apresentado ao entrevistado, construiu-se uma base de dados composta por avaliações sobre a capacidade de liderança efetiva dos Pradhans hipotéticos. O gênero do líder hipotético apresentado nas vinhetas e discursos era sempre mantido o mesmo para o mesmo entrevistado.

Tanto para vinhetas quanto discursos gravados, após sua exibição, os respondentes são indagados questões como "o Pradhan é efetivo?" e "o Pradhan se preocupa com o bem estar dos vilarejos?". Após serem submetidos aos discursos, foram indagados se "o Pradhan deu a devida atenção aos habitantes dos vilarejos", "se alocará os recursos dos programas de transferências sociais bem", "se o Pradhan se esforçaria em obter recursos por meio de lobby", e se "o vilarejo aprovaria o orçamento proposto pelo Pradhan". Após a exposição as vinhetas, perguntaram-lhes "se estão de acordo com a posição expressa pelo Pradhan" e se "votariam naquele Pradhan".

Por meio desta estratégia, objetiva-se isolar questões relativas a diferenças de desempenho (observáveis ou não) entre líderes masculinos e femininos. Caso os respondentes escolham por inferir diferenças entre os desempenhos dos líderes hipotéticos baseadas em seus gêneros, evidencia-se que há de fato discriminação estatística (viés eleitoral contra mulheres).

Para avaliar se tal discriminação de fato existe e, em caso afirmativo, se é afetada pela política de reservas e possíveis efeitos de spillover, empregam-se regressões como as das equações 7 e 8 : 


$$
\begin{gathered}
Y_{i g j}=\delta F_{i g}+\lambda\left(R_{g} * F_{i g}\right)+\mu R_{g}+\theta_{d}\left(N_{d g R}^{T} * F_{i g}\right)+\gamma_{d} N_{d g R}^{T} \\
+\varphi_{d} N_{d g}+X_{i g} \gamma+\alpha_{j}+\epsilon_{i g} \\
Y_{i g j}=\delta F_{i g}+\lambda_{2}\left(R_{g 2} * F_{i g}\right)+\lambda_{2 e 1}\left(R_{g, 2 e 1} * F_{i g}\right)+\lambda_{1}\left(R_{g 1} * F_{i g}\right) \\
+\sum_{k} \mu_{k} R_{k}+\theta_{d 2}\left(N_{d g 2}^{T} * F_{i g}\right)+\theta_{d, 2 e 1}\left(N_{d g, 2 e 1}^{T} * F_{i g}\right)+\theta_{d 1}\left(N_{d g 1}^{T} * F_{i g}\right) \\
+\sum_{k} \gamma_{k} N_{d g k}^{T}+\varphi_{d} N_{d g}+X_{i g} \vartheta+\alpha_{j}+\epsilon_{i g}
\end{gathered}
$$

Em ambas as equações, $Y_{i g j}$ representa uma média das avaliações realizadas pelo entrevistado i, habitante do GP g, pertencente ao quarteirão j, em relação à efetividade do líder hipotético ao qual foi submetido por meio das vinhetas e discursos gravados. $F_{i g}$ é uma dummy que indica se o estímulo recebido pelo entrevistado i, habitante do GP g, foi de uma mulher (se o gênero do líder hipotético era feminino). $X_{i g}$ é um vetor de controles relativos a condições socioeconômicas do respondente i e do GP g em que habita. $\alpha_{j}$ representa efeitos fixos de quarteirões. Novamente, erros padrões são robustos e agrupados pelos GPs, dado o grande número de observações para cada GP.

Na equação $7, R_{g}$ é a dummy que indica se o GP g já foi reservado ao menos vez seja em 1998 e/ou 2003. $N_{d g R}^{T}$ representa o número de GPs dentro de um raio de d $\mathrm{km}$, ao redor do GP g, que foram reservados ao menos uma vez nas eleições passadas. $N_{d g}$, por sua vez indica o número total de GPs dentro de um raio de $\mathrm{d} \mathrm{km}$, ao redor do GP g. Na equação 8, as especificações das variáveis referentes a reservas do GP g e densidades locais de tratamento funcionam exatamente como na equação 6. Novamente, são estimadas regressões para todos os 22 raios disponíveis.

\subsubsection{Resultados}

Na Tabela 4 encontramos os resultados referentes à avaliação de líderes hipotéticos femininos feita por habitantes mulheres, comparativamente às avaliações referentes a líderes hipotéticos masculinos. Deste modo, o resultado original (coluna 0 $\mathrm{km}$ ), apesar de estatisticamente insignificante, implicaria que mulheres em GPs que nunca foram reservados $\left(R_{g}=0\right)$ avaliam líderes hipotéticos femininos 0,035 desvios padrões abaixo de líderes hipotéticos masculinos. 
Como os resultados originais não eram significantes para mulheres, a introdução das variáveis para controlar potenciais efeitos de spillovers apenas poderia alterar os resultados caso fossem suficientemente significantes e de magnitude relevante para que sua omissão subestimasse o viés contra líderes mulheres implícito. Aparentemente não é o caso para respondentes femininas, para as quais nem efeitos diretos das reservas políticas nem efeitos indiretos por meio de spillovers parecem afetar a forma como avaliam líderes de gêneros distintos.

\section{TABELA 4}

Avaliação da efetividade de líderes hipotéticos (vinhetas e discursos)

\begin{tabular}{cccccc}
\hline \hline & \multicolumn{5}{c}{ Efeitos Médios } \\
\cline { 2 - 5 }$N=6780$ & $0 \mathrm{~km}$ & $6 \mathrm{~km}$ & $15 \mathrm{~km}$ & $24 \mathrm{~km}$ & $31 \mathrm{~km}$ \\
\cline { 2 - 5 } & $-0,035$ & $-0,041$ & $-0,014$ & 0,006 & $-0,011$ \\
$n_{\text {Fig }}$ & $(0,031)$ & $(0,041)$ & $(0,057)$ & $(0,062)$ & $(0,060)$ \\
& 0,024 & 0,023 & 0,024 & 0,024 & 0,023 \\
$R_{g} * F_{i g}$ & $(0,038)$ & $(0,038)$ & $(0,038)$ & $(0,038)$ & $(0,038)$ \\
& & 0,005 & $-0,002$ & $-0,002$ & 0,000 \\
$N_{d g R}^{T} * F_{i g}$ & & $(0,017)$ & $(0,004)$ & $(0,002)$ & $(0,001)$ \\
& & 1,61 & 9,94 & 21,87 & 31,17 \\
\hline$N_{d g R}^{T}$ & & &
\end{tabular}

Notas: $\overline{N_{d g R}^{T}}$ representa o número médio de GPs que já foram reservados ao menos uma vez em eleições passadas a uma distância d de um GP representativo g; Todas as regressões foram estimadas por MQO, incluindo efeitos fixos de "quarteirões", erros padrões ajustados para heteroscedasticidade e agrupados em GPs. Os controles utilizados foram: (i) controles a nível do respondente para idade, idade ao quadrado, tamanho da residência, religião, dummies para castas, anos de educação formal, índice de riqueza (baseado nos bens domiciliares que possuem) e dummy para posse de terra; (ii) controles a nível dos GPs para população total, parcela de castas e tribos agendadas, taxa de alfabetização, parcela de mulheres alfabetizadas, dummies para infraestrutura dos GPs (paradas de ônibus ou trem, estradas nacionais, poços, poços com bombas hidráulicas, poços manuais, água encanada comunitária, número de escolas e instalações de saúde pública.

*** significância ao nível de 1\%; ** significância ao nível de 5\%; * significância ao nívelde $10 \%$.

Por sua vez, os resultados para respondentes masculinos, apresentados na Tabela 5, evidenciam exatamente o efeito de omissão de variáveis que capturem spillovers na regressão original (coluna $0 \mathrm{~km}$ ). $\mathrm{O}$ resultado original era apenas fracamente significante quando considerado conjuntamente (teste para 
$F_{i g}+R_{g} * F_{i g}=0$ com p-valor 0,106), apesar de incrivelmente relevante: a exposição de habitantes masculinos a pelo menos uma liderança feminina é o suficiente para mais do que corrigir seu viés inicial contrário a lideranças femininas.

Ao introduzirmos os termos de densidades locais de tratados, as variáveis de efeito direto ganham bastante significância conjunta (para a grande maioria dos raios disponíveis, a significância conjunta dos efeitos diretos é sempre significante a pelo menos o nível de 5\%, permanecendo na maior parte das regressões abaixo de $1 \%$ ). Similarmente, independentemente do raio utilizado os coeficientes estimados para densidade local de tratados ao menos uma vez em eleições passadas permanece sempre fortemente significante. À medida que o raio é aumentado, a magnitude de seu estimador é reduzida, mas seu efeito médio mantém-se relativamente estável uma vez que o número de observações tratadas também aumenta com o aumento dos raios utilizados.

\section{TABELA 5}

\section{Avaliação da efetividade de líderes hipotéticos (vinhetas e discursos)}

\begin{tabular}{|c|c|c|c|c|c|c|c|}
\hline \multirow{3}{*}{$\mathrm{N}=6717$} & \multicolumn{7}{|c|}{ Efeitos Médios } \\
\hline & \multicolumn{7}{|c|}{ Respondentes masculinos } \\
\hline & $0 \mathrm{~km}$ & $6 \mathrm{~km}$ & $15 \mathrm{~km}$ & $24 \mathrm{~km}$ & $31 \mathrm{~km}$ & $38 \mathrm{~km}$ & $44 \mathrm{~km}$ \\
\hline \multirow[t]{2}{*}{$F_{i g}$} & $-0,054 * *$ & $-0,118 * * *$ & $-0,139 * * *$ & $-0,150 * * *$ & $-0,164 * * *$ & $-0,180$ & $-0,181 * * *$ \\
\hline & $(0,027)$ & $(0,035)$ & $(0,044)$ & $(0,049)$ & $(0,048)$ & $(0,048)$ & $(0,049)$ \\
\hline \multirow[t]{2}{*}{$R_{g} * F_{i g}$} & $0,091 * *$ & $0,087 * *$ & $0,091 * *$ & $0,095 * * *$ & $0,095 * * *$ & $0,094 * * *$ & $0,092 * * *$ \\
\hline & $(0,036)$ & $(0,035)$ & $(0,036)$ & $(0,035)$ & $(0,035)$ & $(0,035)$ & $(0,035)$ \\
\hline \multirow[t]{2}{*}{$N_{d g R}^{T} * F_{i g}$} & & $0,042 * * *$ & $0,009 * *$ & $0,004 * *$ & $0,003 * *$ & $0,003 * * *$ & $0,002 * * *$ \\
\hline & & $(0,015)$ & $(0,004)$ & $(0,002)$ & $(0,001)$ & $(0,001)$ & $(0,000)$ \\
\hline$\overline{N_{d g R}^{T}}$ & & 1,61 & 9,94 & 21,87 & 31,17 & 40,50 & 47,95 \\
\hline
\end{tabular}

Notas: $\overline{N_{d g R}^{T}}$ representa o número médio de GPs que já foram reservados ao menos uma vez em eleições passadas a uma distância d de um GP representativo g; Todas as regressões foram estimadas por MQO, incluindo efeitos fixos de "quarteirões", erros padrões ajustados para heteroscedasticidade e agrupados em GPs. Os controles utilizados são os mesmos reportados na Tabela 4.

*** significância ao nível de 1\%; ** significância ao nível de 5\%; * significância ao nível de $10 \%$. 
Além disso, os efeitos de spillover em si são de grande importância. Considerando o raio de $15 \mathrm{~km}$, por exemplo, um habitante masculino de um GP representativo que nunca foi reservado previamente apresentaria um viés contra um líder hipotético feminino 0,049 desvios padrões inferiores ao de um líder hipotético masculino, valor $9 \%$ inferior ao viés obtido pela regressão original. No caso de um habitante masculino em um GP representativo que já tenha sido reservado previamente, sua avaliação esperada seria 0,04146 desvios padrões superiores para líderes hipotéticos femininos, quando comparados a lideres hipotéticos masculinos, valor $12 \%$ superior ao obtido pela regressão original.

A existência de efeitos de spillover, resultantes da política de cotas de gênero, com efeito positivo (redutor de viés) sobre a discriminação estatística representa um mecanismo indireto de grande potencial multiplicador a longo prazo dentro do arcabouço proposto por Beaman et al. (2009), uma vez que ajudaria com a redução da assimetria de informação sobre capacidade de liderança feminina, mesmo em habitantes de GPs que nunca tenham sido reservados (e que possivelmente não venham a ser em eleições futuras).

De posse dos resultados contidos na Tabela 5, os quais foram obtidos utilizando indicadores para ao menos uma reserva em qualquer um dos dois períodos eleitorais anteriores; as regressões representadas pela equação 8 foram estimadas de modo a tentar verificar se o timing das reservas também é relevante para a redução da discriminação estatística.

Os resultados originais (reproduzidos na coluna $0 \mathrm{~km}$ da Tabela 6), reforçam que reservas mais recentes (aquelas de 2003) são as mais relevantes para a redução dos vieses contra lideranças femininas em homens. Os resultados reiteram que a forma como mulheres avaliam seus líderes também não parece ser afetada pelo histórico de reservas políticas dos GPs em que vivem, quando estas são consideradas em categorias exclusivas.

A introdução de variáveis de densidade de tratados aqui apresenta um efeito interessante (apenas para respondentes homens): apesar de as estimativas para os efeitos de spillover apenas serem significantes para os raios menores que $9 \mathrm{~km}$ (especialmente a densidade de tratados exclusivamente em 2003), as estimativas dos coeficientes de efeito direto $\left(F_{i g}+R_{g 2} * F_{i g}\right)$ se tornam mais significantes e de magnitudes mais expressivas, independentemente dos raios utilizados, quando comparados aos resultados sem a incorporação de efeitos de spillover. 
TABELA 6

Avaliação da efetividade de líderes hipotéticos (vinhetas e discursos)

\begin{tabular}{|c|c|c|c|c|c|c|}
\hline & \multicolumn{6}{|c|}{ Efeitos Médios } \\
\hline & \multicolumn{3}{|c|}{ Homens } & \multicolumn{3}{|c|}{ Mulheres } \\
\hline & $0 \mathrm{~km}$ & $6 \mathrm{~km}$ & $9 \mathrm{~km}$ & $0 \mathrm{~km}$ & $6 \mathrm{~km}$ & $15 \mathrm{~km}$ \\
\hline \multirow[t]{2}{*}{$F_{i g}$} & $-0,053 * *$ & $-0,118 * * *$ & $-0,122 * * *$ & $-0,034$ & $-0,040$ & $-0,016$ \\
\hline & $(0,027)$ & $(0,035)$ & $(0,039)$ & $(0,030)$ & $(0,039)$ & $(0,056)$ \\
\hline \multirow{2}{*}{$R_{g 2} * F_{i g}$} & $0,112^{* *}$ & $0,134 * * *$ & $0,114 * *$ & $-0,001$ & 0,011 & $-0,003$ \\
\hline & $(0,047)$ & $(0,045)$ & $(0,045)$ & $(0,048)$ & $(0,050)$ & $(0,046)$ \\
\hline \multirow[t]{2}{*}{$R_{g, 2 e 1} * F_{i g}$} & 0,092 & $0,099 *$ & 0,092 & 0,052 & 0,059 & 0,049 \\
\hline & $(0,062)$ & $(0,058)$ & $(0,061)$ & $(0,060)$ & $(0,057)$ & $(0,060)$ \\
\hline \multirow[t]{2}{*}{$R_{g 1} * F_{i g}$} & 0,073 & 0,057 & 0,065 & 0,035 & 0,027 & 0,042 \\
\hline & $(0,046)$ & $(0,045)$ & $(0,045)$ & $(0,045)$ & $(0,046)$ & $(0,046)$ \\
\hline \multirow[t]{2}{*}{$N_{d g 2}^{T} * F_{i g}$} & & $0,058 * * *$ & $0,029 *$ & & 0,020 & $-0,010$ \\
\hline & & $(0,022)$ & $(0,016)$ & & $(0,022)$ & $(0,014)$ \\
\hline \multirow[t]{2}{*}{$N_{d g, 2 e 1}^{T} * F_{i g}$} & & $0,069^{* *}$ & 0,009 & & 0,029 & 0,000 \\
\hline & & $(0,032)$ & $(0,020)$ & & $(0,036)$ & $(0,011)$ \\
\hline \multirow[t]{2}{*}{$N_{d g 1}^{T} * F_{i g}$} & & 0,004 & 0,012 & & $-0,026$ & 0,004 \\
\hline & & $(0,024)$ & 0,016 & & $(0,027)$ & $(0,014)$ \\
\hline
\end{tabular}

Notas: Todas as regressões foram estimadas por MQO, incluindo efeitos fixos de "quarteirões", erros padrões ajustados para heteroscedasticidade e agrupados em GPs. Os controles utilizados são os mesmos reportados na Tabela 4.

*** significância ao nível de 1\%; ** significância ao nível de 5\%; * significância ao nível de $10 \%$.

Conjuntamente os resultados indicam que, apesar de efeitos de spillover não serem observados em melhorias das condições eleitorais de mulheres desde o início da política de reservas políticas (Tabelas 2 e 3) para além das fronteiras dos GPs que de fato já foram reservados duas vezes seguidas; o forte viés eleitoral contra lideranças femininas está sendo amenizado tanto direta quanto indiretamente pela política pública.

Isto implica que a quebra do ciclo vicioso exposto em Beaman et al. (2009) pode se dar de maneira mais acelerada do que os resultados originais, apenas com efeitos diretos, sugeririam. A presença de spillovers positivos sobre a percepção de efetividade de lideranças femininas, pelos habitantes masculinos, pode acelerar o processo de erosão da discriminação estatística. 
Torna-se possível, com o passar das eleições e sucessivas reservas, até mesmo uma reversão dos resultados para spillovers sobre participação política feminina em eleições para conselhos de GPs e Pradhans, haja vista o papel informacional dos spillovers verificados sobre a redução de risco eleitoral para candidatas femininas.

\section{Considerações finais}

O número de pesquisas destinadas a avaliar possíveis efeitos de spillover de políticas públicas ainda é bastante reduzido na literatura econômica, apesar dos benefícios discutidos e verificados nos resultados em termos de eficiência metodológica.

Políticas públicas que geram grande impacto social, político e econômico como é o caso de cotas de gênero - são especialmente susceptíveis a serem afetadas por efeitos de spillover, uma vez que discussões de questões referentes a política e qualidade de vida local são centrais no processo de difusão de informação e formação de redes sociais.

Com os resultados aqui obtidos, espera-se contribuir para esta literatura e ampliar a percepção sobre a relevância de se incluírem efeitos de spillover de modo a captar os impactos reais, tanto diretos quanto indiretos, de políticas de cotas de gênero e tantas outras políticas públicas de cunho fortemente social.

A base de dados utilizada, tal como disponibilizada por Beaman et al. (2009) refere-se às eleições de 2008. Desde então, uma outra eleição já foi realizada em 2013, abrindo possibilidade para atualização dos resultados e verificação mais profunda dos efeitos temporais da política de cotas, passados já mais de 15 anos desde sua implementação. 


\section{Referências Bibliográficas}

ANGELUCCI, M.; DE GIORGI, G. Indirect Effects of an Aid Program: How do Cash Injections Affect Ineligibles' Consumption? American Economic Review, 99 (1), p. 486508, 2009.

ANGELUCCI, M.; DI MARO, V. Program evaluation and spillover effects. Policy Research working paper; no. WPS7243; Impact Evaluation Series. Washington, D.C.: World Bank Group, 2015.

AVITABILE, C. Spillover Effects in Healthcare Programs: Evidence of Social Norms and Information Sharing. IDB Working Papers Series N. IDB-WP-380, 2012.

BAN, R.; RAO, V. Tokenism or agency? The impact of women's reservations on village democracies in South India. Economic Development and Cultural Change, 56, p. 50130, 2008.

BANERJEE, A.; CHANDRASEKHAR, A. G.; DUFLO, E.; JACKSON, M. O. The diffusion of microfinance. Science, 341 (6144), 2013.

BARDHAN, P.; MOOKHERJEE, D. Decentralizing antipoverty program delivery in developing countries. Journal of Public Economics, 89 (4), p. 675-704, 2005.

BEAMAN, L.; CHATTOPADHYAY, R.; DUFLO, E.; PANDE, R.; TOPALOVA, P. Powerful women: Does exposure reduce bias? Quarterly Journal of Economics, 124 (4), p. 1497-540, 2009.

BEAMAN, L; DUFLO, E.; PANDE, R. TOPALOVA, P. Female leadership raises aspirations and educational attainment for girls: A policy experiment in India. Science, 335 (6068), 582-86, 2012.

BESLEY, T; COATE, S. An economic model of representative democracy. Quarterly Journal of Economics, 112 (1), p. 85-114, 1997.

BHAVNANI, R. R. Do electoral quotas work after they are withdrawn? Evidence from a natural experiment in India. American Political Science Review, 103 (1), p. 23-35, 2009.

BOBONIS, G. J.; FINAN, F. Neighborhood Peer Effects in Secondary School Enrollment Decisions. Review of Economics and Statistics, 91(4), p. 695-716, 2009.

BROLLO, F.; TROIANO, U. What happens when a woman wins an election? Evidence from close races in Brazil. CAGE Online Working Paper Series 161, 2013.

CHATTOPADHYAY, R; DUFLO, E. Women as policymakers: Evidence from a randomized policy experiment in India. Econometrica, 72 (5), p. 1409-43, 2004. 
DEVOTO, F.; DUFLO, E.; DUPAS, P.; PARIENTÉ, W.; PONS, V. Happiness on Tap: Piped Water Adoption in Urban Morocco. American Economic Journal: Economic Policy, 4 (4), p. 68-99, 2012.

DI TELLA, R.; SCHARGRODSKY, E. Do Police Reduce Crime? Estimates Using the Allocation of Police Forces After a Terrorist Attack. American Economic Review, 94 (1), p. 115-133, 2004.

DOWNS, A. An economic theory of democracy. Boston, MA: Addison Wesley, 1957.

DUFLO, E.; UDRY, C. Intrahousehold resource allocation in Côte D'ivoire: Social norms, separate accounts and consumption choices. NBER Working Paper 10498, 2004.

EDLUND, L.; PANDE, R. Why have women become left-wing? The political gender gap and the decline in marriage. Quarterly Journal of Economics, 117 (3), p. 917-961, 2002.

FOX, R. L.; LAWLESS, J. Entering the arena? Gender and the decision to run for office. The American Journal of Political Science, 48, p. 264-80, 2004.

GOLDIN, C.; ROUSE, C. Orchestrating impartially: The impact of blind auditions on female musicians. American Economic Review, 90 (4), p. 715-41, 2000.

HECKMAN, J..; LALONDE, R..; SMITH, J. The economics and econometrics of active labor market programs. In: O. Ashenfelter; D. Card (ed.), Handbook of Labor Economics, $1^{\text {a }}$ edição, vol. 3, cap. 31, p. 1865-2097, Elsevier, 1999.

JACKSON, M. O. An overview of social networks and economic applications. IN: J. Benhabib; A. Bisin; M. O. Jackson (ed.), Handbook of Social Economics, $1^{\text {a }}$ edição, vol. 1, cap. 12, p. 511-85, Elsevier, 2011.

KROOK, M. L. Quotas for women in politics: Gender and candidate selection worldwide. New York e London: Oxford University Press, 2009.

LEHMANN, C. Beneficiando-se sem receber dinheiro? Externalidades dos programas de transferência condicionada de renda na escolaridade, saúde e na economia comunitária. IPC, Policy Research Brief $\mathrm{n}^{\circ}$ 13, 2010. Disponível em $\leq$ http://www.ipcundp.org/pub/port/IPCPolicyResearchBrief13.pdf>.

LEHMANN, C. Long-run effects of conditional cash transfers. In: $41^{\circ}$ Encontro de Economia - ANPEC, 2013.

LEVITT, S. How do senators vote? Disentangling the role of voter preferences, party affiliation, and senator ideology. American Economic Review, 86 (3), p. 425-41, 1996.

LOTT, J. R.; KENNY, L. W. Did women's suffrage change the size and scope of government? Journal of Political Economy, 107 (6), p. 1163-98, 1999. 
MIGUEL, E., KREMER, M. Worms: Identifying Impacts on Education and Health in the Presence of Treatment Externalities. Econometrica, 72 (1), p. 159-217, 2004.

MILLER, G. Women's suffrage, political responsiveness, and child survival in American history. Quarterly Journal of Economics, 123 (3), 1287-327, 2008.

OSBORNE, M. J.; SLIVINSKI, A. A model of political competition with citizencandidates. Quarterly Journal of Economics, 111 (1), p. 65-96, 1996.

PANDE, R. Can mandated political representation increase policy influence for disadvantaged minorities? Theory and evidence from India. American Economic Review, 93 (4), p. 1132-51, 2003.

REINGOLD, B. Concepts of representation among female and male state legislators. Legislative Studies Quarterly, 17 (4), p. 509-537, 1992.

SAINT-GERMAN, M. A. Does their difference make a difference? The impact of women on public policy in the Arizona Legislature. Social Science Quarterly, 70, p. 956-968, 1989.

WILKINSON, S. I. India, consociational theory and ethnic violence. Asian Survey, 40, p. 767-791, 2000.

YANG, D. Can Enforcement Backfire? Crime Displacement in the Context of Customs Reform in the Philippines. Review of Economics and Statistics, 90 (1), p. 1-14, 2008. 